\title{
Spectrum of Magnetic Resonance Imaging Findings in Patients with Head Injury in a Nigerian Population
}

\author{
Chukwuani Anselm Ejike ${ }^{1}$, Omiyi David Oselumenosen², Eneje Obinna Franklin ${ }^{3}$ \\ ${ }^{1}$ Department of Radiology, Reddington Hospital, Lagos, Nigeria \\ ${ }^{2}$ Department of Radiation Biology, Radiotherapy, Radiodiagnosis and Radiography, College of Medicine, University of Lagos, \\ Lagos, Nigeria \\ ${ }^{3}$ Department of Radiology, Garki General Hospital, Abuja, Nigeria
}

\section{Email address:}

anselm.chukwuani@gmail.com (A. E. Chukwuani)

\section{To cite this article:}

Chukwuani Anselm Ejike, Omiyi David Oselumenosen, Eneje Obinna Franklin. Spectrum of Magnetic Resonance Imaging Findings in Patients with Head Injury in a Nigerian Population. International Journal of Psychological and Brain Sciences.

Vol. 2, No. 4, 2017, pp. 92-94. doi: 10.11648/j.ijpbs.20170204.11

Received: May 16, 2017; Accepted: May 24, 2017; Published: July 7, 2017

\begin{abstract}
Head injury is a pressing public health concern the world over. Head injury and associated traumatic brain injury (TBI) usually result in neurocognitive impairments and psychological health issues especially when underlying chronic sequalae are not promptly diagnosed and managed. Magnetic resonance imaging (MRI) has been found to be the most sensitive imaging modality for the evaluation of lesions secondary to head injury. This study examined the spectrum of MRI findings in head injury cases in a population within South western Nigeria. A prospective study of MRI findings in 163 patients who presented to the radiology department of a foremost teaching hospital in South-western Nigeria with clinical history of head injury was undertaken for a period of 2 years (from January 2015 to December 2016). The following data were obtained and studied: demographic data, clinical history and MRI findings. The MR images were obtained with a 1.5Tesla Siemens MR Scanner. Both T1-weighted and T2-weighted MR imaging protocols were performed for all the patients. The MR images were acquired by the radiographers and interpreted by consultant radiologists. $121(74.23 \%)$ of the subjects were males while 42 $(26.76 \%)$ were females. Road traffic accident (RTA) $(n=87,53.37 \%)$ was the major cause of head injury sustenance in more than half of the entire cases evaluated. The most common MRI findings are subdural haematoma $(\mathrm{n}=41,25.14 \%)$; cerebral contusion $(n=27,16.56 \%)$; subarachnoid haemorrhage $(n=19,11.65 \%)$; cerebral infarction $(n=12,7.36 \%)$; skull fracture $(n$ $=11,6.74 \%)$; cerebral atrophy $(\mathrm{n}=10,6.13 \%)$ and multiple sclerosis $(\mathrm{n}=7,4.30 \%)$. The least common findings are leucoencephalopathy $(n=5,3.06 \%)$ and retained bullet $(n=5,3.06 \%)$. Magnetic resonance imaging is a paramount imaging modality in the diagnosis of lesions secondary to head injury. Thus the need to make MRI facilities more available in healthcare settings of developing countries, like Nigeria, is re-emphasised.
\end{abstract}

Keywords: Head Injuries, Medical Imaging, Magnetic Resonance Imaging

\section{Introduction}

Head injury is a common incidence in both urban and rural settings; secondary to multiple causes [1]. Head injuries represent a spectrum of clinical conditions involving the cranium, its covering and contents following trauma [2]. The imaging of head injury has evolved along with the advances experienced in diagnostic imaging as a whole [3].

Often, computed tomography (CT) is the first imaging test performed in an emergency setting for the evaluation of head injury $[4,5]$. The goal of emergency $\mathrm{CT}$ imaging is to depict lesions that might need urgent medical/neurosurgical intervention within the first 48 hours of head injury incidence ${ }^{4}$. Magnetic resonance imaging (MRI), on the other hand, is usually reserved for showing lesions that could explain clinical symptoms and signs that are not explained by prior CT, to help better define abnormalities not well seen on $\mathrm{CT}$, and/or to rule out important chronic sequel [5-8].

Today, MRI of the brain is increasingly used both in research and in clinical medicine. Performing MRI at higher resolution, field strength and with more sensitive sequences leads to the detection of subtle or small brain abnormalities that would not 
have been detected previously, following trauma [7]. The increased sensitivity of MRI relative to CT for detection of many forms of brain injury has been well-documented $[5,7,8]$.

Magnetic resonance imaging studies of the brain is considered a better imaging technique than $\mathrm{CT}$ for two reasons. First, MRI has a much higher contrast resolution when compared with $\mathrm{CT}$ for exquisite depiction of normal anatomical structures and pathologies of the brain. Unlike CT angiography, intravenous contrast injection is not required for MR angiography. This is advantageous in patients with impaired renal function, contrast allergy or no intravenous access. Secondly, MRI does not involve radiation exposure. Brain CT scans which use X-rays to produce images may expose patients to about $2 \mathrm{mSv}$ of radiation which is twenty times that of chest X-rays [9]. In simple terms, the radiation exposure from one non-contrast CT brain study is equivalent to the amount of background radiation one experiences in about 8 months [9]. In spite of all benefits of MRI of brain imaging, no studies have been done to investigate the common findings of brain MRI in head injury in an African population. This research was designed to examine the pattern of MRI findings in head injury cases in an indigenous population within South-west Nigeria.

\section{Methods}

This non-experimental and prospective research was carried out in a foremost Teaching Hospital in South-western Nigeria. A total of 163 patients' MRI records were evaluated. We studied cases that met the inclusion criteria from January 2015 to December 2016. The MR images were obtained with a 0.2 Tesla Siemens MR Scanner. Data collected was tallied and analysed using Statistical Package for Social Sciences software (SPSS v. 17).

\section{Results}

A total of 163 brain MRI cases were studied (Table 1). 121 (74.23\%) were males while $42(26.76 \%)$ were females. Age range was 4-85 years with mean of $49.52 \pm 15.11$ years, while most of the patients were in the age group of 41-60 years $(\mathrm{n}=$ $61,47.7 \%$ ). The age distribution of head injury cases shows that the age group 21-30 had the highest frequency of head injury cases $(\mathrm{n}=45,27.60 \%)$ of the population while age group $>80$ has least frequency $(n=1,0.61 \%)$. More males $(n=$ $121,74.23 \%$ ) are involved in head injury cases than females (n $=42,25.76 \%$ ) out of the total population. Again, males aged 21-30 had the highest number of head injury cases.

Table 1. Distribution of Gender and Age of Head Injury Cases.

\begin{tabular}{|c|c|c|c|c|}
\hline \multirow{2}{*}{$\begin{array}{l}\text { Age } \\
\text { group }\end{array}$} & \multicolumn{2}{|c|}{ Gender } & \multirow{2}{*}{$\begin{array}{l}\text { Total } \\
\text { Freq }\end{array}$} & \multirow{2}{*}{$\begin{array}{l}\text { Total } \\
\text { Percentage (\%) }\end{array}$} \\
\hline & Male & Female & & \\
\hline $0-10$ & 5 & 3 & 8 & 4.90 \\
\hline $11-20$ & 17 & 13 & 30 & 18.40 \\
\hline $21-30$ & 37 & 8 & 45 & 27.60 \\
\hline $31-40$ & 35 & 6 & 41 & 25.15 \\
\hline $41-50$ & 10 & 4 & 14 & 8.58 \\
\hline $51-60$ & 7 & 4 & 11 & 6.75 \\
\hline
\end{tabular}

\begin{tabular}{|c|c|c|c|c|}
\hline \multirow{2}{*}{$\begin{array}{l}\text { Age } \\
\text { group }\end{array}$} & \multicolumn{2}{|l|}{ Gender } & \multirow{2}{*}{$\begin{array}{l}\text { Total } \\
\text { Freq }\end{array}$} & \multirow{2}{*}{$\begin{array}{l}\text { Total } \\
\text { Percentage (\%) }\end{array}$} \\
\hline & Male & Female & & \\
\hline $61-70$ & 6 & 2 & 8 & 4.90 \\
\hline $71-80$ & 3 & 2 & 5 & 3.06 \\
\hline$>80$ & 1 & 0 & 1 & 0.61 \\
\hline Total & $121(74.23 \%)$ & $42(25.76 \%)$ & 163 & 100.00 \\
\hline
\end{tabular}

Road Traffic Accident (RTA) ( $\mathrm{n}=87,53.37 \%$ ) was the leading cause of head injury in the population studied followed by gunshot injury $(\mathrm{n}=13,7.97 \%)$ as shown on Table 2. Head injury resulting from sudden collapse has least frequency $(\mathrm{n}=11,6.47 \%)$

Table 2. Causes of Head Injury.

\begin{tabular}{lll}
\hline Causes & Frequency (n) & Percentage (\%) \\
\hline RTA & 87 & 53.37 \\
Gunshot Injury & 13 & 7.97 \\
Fall & 12 & 7.36 \\
Assault & 11 & 6.74 \\
Seizure & 7 & 4.29 \\
Collapse & 11 & 6.74 \\
Not defined & 22 & 13.49 \\
Total & 163 & 100.00 \\
\hline
\end{tabular}

The most common MRI findings are haematoma $(\mathrm{n}=32$, $19.63 \%$ ) followed by cerebral contusion $(\mathrm{n}=27,16.56 \%)$; subarachnoid haemorrhage $(\mathrm{n}=15,9.20 \%)$; intracranial haemorrhage $(n=13,7.97 \%)$; cerebral infarction $(n=12$, $7.36 \%)$; skull fracture $(\mathrm{n}=11,6.74 \%)$; cerebral atrophy $(\mathrm{n}=$ $10,6.13 \%)$ and multiple sclerosis $(\mathrm{n}=7,4.30 \%)$ (Table 3$)$. The least common findings are leucoencephalopathy $(\mathrm{n}=5$, $3.06 \%)$ and retained bullet $(n=5,3.06)$. They are $6(3.68 \%)$ cases of less common forms of lesions noted but not documented in this study. The radiological reports of 2 patients $(1.22 \%)$ were not found while there was normal MRI findings in 9 cases $(5.52 \%)$. Finally, it is important to appreciate that MRI yielded positive findings in 152 cases (93.25\%) while 9 cases $(5.25 \%)$ were negative for any lesion on MRI.

Table 3. MRI Findings in Head Injury.

\begin{tabular}{llll}
\hline S/N & Findings & Frequency & Percentage (\%) \\
\hline 1 & Leucoencephalopathy & 5 & 3.06 \\
2 & Intracranial Haemorrhage & 13 & 7.97 \\
3 & Cerebral Infarction & 12 & 7.36 \\
4 & Haematoma & 32 & 19.63 \\
5 & Cerebritis & 9 & 5.52 \\
6 & Fracture & 11 & 6.74 \\
7 & Cerebral Contusion & 27 & 16.56 \\
8 & Cerebral atrophy & 10 & 6.13 \\
9 & Retained bullet & 5 & 3.06 \\
10 & Subarachnoid Haemorrhage & 15 & 9.20 \\
11 & Multiple Sclerosis & 7 & 4.30 \\
12 & Others & 6 & 3.68 \\
13 & No findings & 9 & 5.52 \\
13 & No report & 2 & 1.22 \\
Total & & 163 & 100.00 \\
\hline
\end{tabular}

\section{Discussions}

Head injury often represents a unique clinical challenge, because of its likely association with combination of diffuse and/or focal intracranial lesions [1, 3]. Though computed 
tomography (CT) typically shows mostly subcranial and extracranial damages when they are pronounced, it is clear that MRI is more sensitive than CT in the assessment of posttraumatic lesions of the brain $[4,7]$.

This study shows that individuals in the age range 21-30 $(\mathrm{n}=$ $45,27.60 \%$ ) are found to be more prone to head injury; males having a total number of 35 cases and female 8 , cases. This finding is in agreement with the study by Crippen ${ }^{10}$ who found that traumatic brain injury is much more common in persons younger than 35 years of age. The high incidence of head injury cases in the 21-30 years age group as noted in this study may be primarily due to the fact that this age tend to exhibits youthful exuberance. They are very active and have all it takes to do strenuous jobs. Most people in this age group engage in so many activities that will predispose them to head injury like driving, riding of motorcycle, and sports.

Road traffic accident (RTA) $(n=87,53.37 \%)$ is the major cause of head injury sustenance in more than half of the patients evaluated in this study. This finding agrees with Nzegwu ${ }^{11}$ who stated that RTA is one of the leading causes of morbidity and mortality in individuals aged 50 years and below in Nigeria. These results further reinforce the evidence found by a previous study that the peak incidence of road accident head injury was seen in the most productive years of life ${ }^{12}$. The most prevalent MRI findings are haematoma $(\mathrm{n}=32$, $19.63 \%)$; cerebral contusion $(n=27,16.56 \%)$; subarachnoid haemorrhage $(\mathrm{n}=15,9.20 \%)$; intracranial haemorrhage $(\mathrm{n}=$ $13,7.97 \%)$; cerebral infarction $(\mathrm{n}=12,7.36 \%)$; fracture $(\mathrm{n}=$ $11,6.74 \%)$; cerebral atrophy $(\mathrm{n}=10,6.13 \%)$ and multiple sclerosis $(n=7,4.30 \%)$. The least common findings are leucoencephalopathy $(\mathrm{n}=5,3.06 \%)$ and retained bullet $(\mathrm{n}=$ $5,3.06 \%$ ). With the aid of MRI, the clinicians were able to detect some insidious pathologies like leucoencephalopathy $(\mathrm{n}=5,3.06 \%)$, multiple sclerosis $(\mathrm{n}=7,4.30 \%)$, and cerebritis $(n=9,5.52 \%)$, that arise due to cerebral damage sustained from brain injury which skull radiography and CT might not have revealed. This wide spectrum of findings were obtained probably because most of the patients were examined several days/weeks after sustaining head injury. As a result, some findings were lesions developed as chronic sequela secondary to brain injury. Furthermore, few lesions diagnosed were deemed to be entirely incidental. The pattern of findings encountered in this study are in line with the studies of Trifan et $\mathrm{al}^{13}$ which highlighted the sensitivity of MRI when used as a follow-up modality in the evaluation of head injury particularly when it's closed and blunt.

Finally, there were positive findings in 93.25 percent of the cases $(n=153)$ while only 5.25 percent of the cases $(n=9)$ turned out negative for any lesion on MRI. This observation agrees with previous studies that found that MRI has high sensitivity and diagnostic yield of $(>90 \%)$ in the evaluation of patients with head injury $[7,14,15]$.

\section{Conclusion}

Although CT usually play an urgent role in the preliminary assessment of head injury, this study has shown that MRI is indispensable in the evaluation of lesions that could explain secondary clinical symptoms and signs, to help define abnormalities not well seen on $\mathrm{CT}$, and/or for the evaluation of important chronic sequela. Thus the need to make MRI facilities more available in healthcare settings of developing countries, like ours, is re-emphasised.

\section{References}

[1] Currie S, Saleem N, Straiton JA, et al Imaging assessment of traumatic brain injury Postgraduate Medical Journal 2016; 92: 41-50.

[2] Eieruda C, Craddockc R, Sean Fletchere, Manek Aulakhe, Brooks King-Casasa. Neuroimaging after mild traumatic brain injury: Review and meta-analysis. NeuroImage: Clinical. 2014; 4: 283-294.

[3] Zee $\mathrm{C}$ and Go J. Imaging of Head Trauma-Neuroimaging Clinics of North America. American Journal of Neuroradiology. 2003; 24: 1725-1726.

[4] Meehan WP, d'Hemecourt P, Collins C, Comstock RD. Assessment and Management of Sport-Related Concussions in United States High Schools. Am. J. Sports Med. 2011; 20(10).

[5] Lee B and Newberg A. Neuroimaging in Traumatic Brain Imaging. NeuroRx. 2005; 2(2): 372-383.

[6] Buttram SD, Garcia-Filion P, Miller J, et al. Computed tomography vs. magnetic resonance imaging for identifying acute lesions in pediatric traumatic brain injury. Hosp. Pediatr. $2015 \mathrm{Feb}$; 5(2): 79-84.

[7] Provenzale, James M. Imaging of Traumatic Brain Injury: A Review of the Recent Medical Literature, American Journal of Radiology. 2010; 194: 16-19.

[8] Anderson T, Heitger M, and Macleod A. D. Concussion and Mild Head Injury. Practical Neurology. 2006; 6: 342-357.

[9] Yuh E, Mukherjee P, Lingsma H. Magnetic Resonance Imaging Improves 3-Month Outcome Prediction in Mild Traumatic Brain Injury. Annals of Neurology. 2013; 73: 224-235.

[10] Crippen David. Incidence of Head Trauma in the General Populace, Emergency Care. 2008; (50)4: 11.

[11] Nzegwu M, A study of drivers involved in road traffic accident (RTA) in Benin-city Nigeria: Journal of Medical Sciences and Hospital Management 2005; (1): 25-7.

[12] Gupta P K, CT Scan Findings and Outcomes of Head Injury Patients: A Cross Sectional Study. Journal of Pioneering Medical Sciences. 2011; 1 (3).

[13] Trifan Gabriela, Gattu Ramtilak, Ewart Mark Haacke, Zhifeng Kou. MR imaging findings in mild traumatic brain injury with persistent neurological impairment. Magnetic Resonance Imaging. 2017; 37, 243-251.

[14] Harvey Levin, Williams David, Howard M Eisenberg, Walter M High Jr, Faustino C Guinto Jr, Serial MRI and neurobehavioural findings after mild to moderate closed head injury, Journal of Neurology, Neurosurgery, and Psychiatry 2001; 55: 255-262.

[15] Adams JH, Graham DI, Murray LS, Scott G. Diffuse axonal injury due to nonmissile head injury in humans: An analysis of 45 cases. Annals of Neurology. 2005; 12: 557-63. 